\title{
Collegiality and career success
}

\section{How one's medical school learning environment can affect one's sense of personal and pro- fessional fulfillment decades after graduation}

\author{
Dr Gerald Schneiderman, MD (Class of 1958), PsychD, FRCPC, DLFAPA, DFCPA
}

\begin{abstract}
Success in one's career and life are subjectively determined. However, the presence or absence of regrets are good indicia of one's sense of fulfillment. In the context of professional education, "learning environment" is a key predictor of one's future sense of fulfillment. Collegiality, mutual support, and decency towards one's classmates were considered by the author in this small-scale study to be important predictors of one's later success in life and medical practice.
\end{abstract}

\section{INTRODUCTION}

Various large-scale retrospective studies have considered the relationship between academic success and subsequent career success. The opinion that success in one's career is directly linked to one's academic achievement fails to account for a far more important predictor: the individual's learning environment. Learning environments that foster collegiality and decency is a key predictor of career success. In this small-scale study, the author surveyed 33 of his classmates from the medical school class of 1958, The University of Western Ontario. In the author's own experience, his classmates fostered a positive learning environment defined by decency, collegiality, and valuing the collective over the individual. More than five decades later, the author surveyed his classmates, inquiring about their life and career satisfaction, advice to the younger generation, and also the presence or absence of regrets. 18 responses were received. From the responses, the author illustrates how the collegiality of his classmates continued throughout their lives, leading to greater success personally and professionally.

\section{BACKGROUND AND METHODOLOGY}

Previous studies examining academic achievement and subsequent career satisfaction have emphasized grades and academic achievement. Wingard and Williamson state, "In medicine many crucial decisions regarding the physician's career development are based on traditional grades that often reflect little other than an ability to memorize isolated facts. The need to study both grades and performance is self-evident; the need to rethink the use of grades for crucial career decisions and training grant awards seems to be equally evident."

The author conducted an email survey of his classmates from the medical school of The University of Western Ontario more than five decades after graduation. 33 questionnaires asked the 1958 class:
1. Please describe what your work after studying medicine at Western was like. Did you remain in medicine? If so, did you practise? Research? Write? What else did you do? Did you receive accolades and/or awards? Are you willing to share a copy of your most up-todate curriculum vitae?

2. Please describe your personal life to the extent that you are comfortable in doing so. Are you still working, fully retired, or partially retired? Do you have any relationships or family you wish to mention? What did you do that "defined" you beyond your work life (hobbies, passions, pursuits of any kind)?

3. If you were to give advice to your younger self, prior to going to med-school, what would you say? Would you want your younger self to know what lay ahead? Or would you want it to remain an unknown? Is there anything you would want to try to change, looking back?

18 responses were received, either by email or in hardcopy. Of those who responded, their answers were detailed, insightful, and emphasized the value of meaning in life, not just within one's own aspirations, but also as a community.

\section{THE AUTHOR'S IMPRESSIONS OF THE COHORT}

The author had regarded his classmates as having wanted the best not just for themselves, but also each other. Collegiality was at the core of their collective aims. Each of them was ambitious in their own rights; despite everyone wanting to be singularly outstanding, such ambitions never undermined the collegiality and support that they provided one another throughout medical school.

\section{SURVEY RESULTS FROM THE AUTHOR'S MEDICAL SCHOOL CLASS}

The interactions amongst the author's peers were defined by sincerity and decency and were aimed at elevating the group as a whole, rather than individuals at the expense of the group. The author's classmates' values of good will, civility, and collegiality were subsequently confirmed in their careers and personal lives. His classmates' collective answers to the questionnaire, as a whole, pointed to a broader conclusion beyond any one individual response: decency and humanity lead to more fulfilling careers than selfishness and solitary ambition.

After excluding personal identifying information and personal anecdotes (such as shared memories and anecdotes), the author extracted from the survey responses comments of a more gener- 
al nature that addressed each participants' sense of life and career success. Some of the responses were provided in response to each question, but most were provided in the form of narrative responses answering all questions globally. The author considered that the paucity of regrets is particularly noteworthy. Extracts from the questionnaire are presented below:

- "To start with, I would not change a thing in my life."

- "I had a very busy medical and family life and I would not change any of it. I would even keep my medical school classmates."

- "I did enjoy my 30 plus years in practice, but have to admit I don't miss it."

- "I am happily engaged with family and community."

- "I have no regrets about my career path."

- "I have lived a happy and blessed life."

- "I would change nothing about my past. I am satisfied, happy, with moments of sadness about the passing of time, and I loved practising medicine."

- "Advice to the young: Have faith in God; don't listen to your agnostic professors. They know very little about life outside of a university."

- "Practice virtue; be prudent, be temperate; be just; have courage; take prudent risks; love people, even the obnoxious and ignorant. [T] each them to be prudent and loving." [complete quote]

- "Greatest virtue: patience - it conquers the world. And be cause very few others have it, you win out of endurance!"

- "God and faith, with a touch of reason, are not contradictory."

- "Choices made by current medical school students should be their own, and not my rose-coloured recollections."

- "I trust that I am defined as a decent human being, a good husband, a good father, and a good grandfather."

- "I try to keep promises that I make and wish to be known as a reliable, educated and interesting person."

- "I wish I had learned how to play golf and card games, and in my academic career, I wish I had written more. Other than these, I have had a rich life and would not have changed anything."

- "Physicians must be prepared to be parts of teams, to never find the making of money the primary effort, to provide the appropriate times required to satisfy patients, to easily accept sending patients to other physicians when he or she is less aware than others of management of the [patients'] illness, etc."

- "I certainly look back and wonder why the hell I didn't do more volunteering within the community, province, country, and the globe, etc."

- "I have felt very strongly upset in not having joined 'Doctors Without Borders' on the one hand."

- "I wish I had worked more to help the healthcare in many of the poor countries."

- "If you can look out the window and truly enjoy nature, you are really alive.”
The entirety of the survey pointed to the value that all of my class placed on helping others. Decency and humanity at the core of the individual and collective values. No regrets were expressed regarding the participants' values of decency, collegiality, and humanity. Indeed, the only regrets expressed were that these doctors could not have helped others as much as they had already done so.

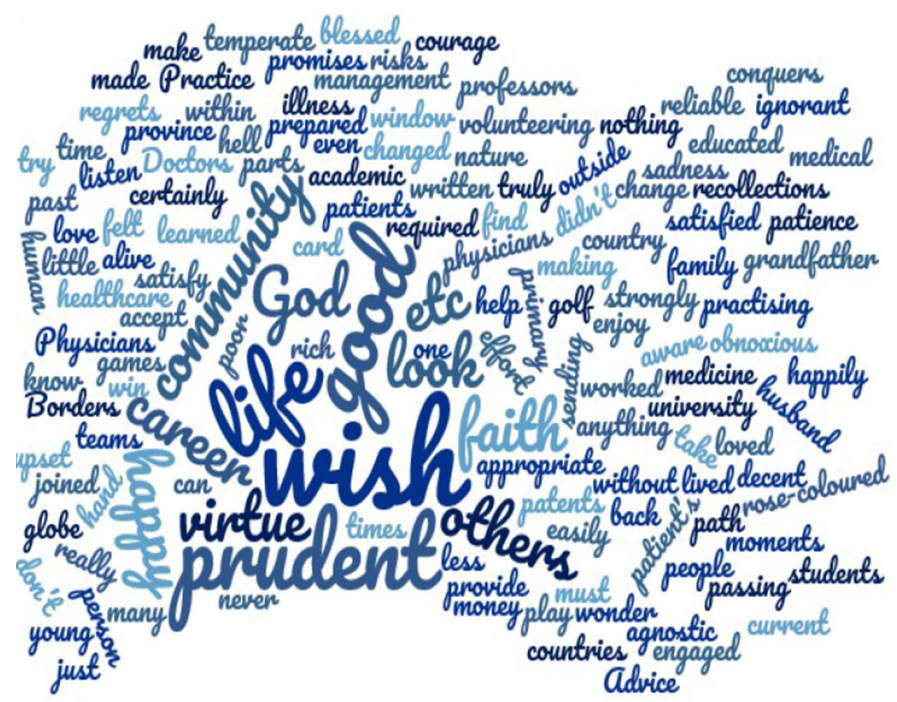

Figure 1. Word cloud generated from survey response statements.

\section{DISCUSSION AND CONCLUSION}

One's learning environment is central to his or her later career satisfaction. In one study of 3,324 Dutch university graduates, the authors observed that "... high-quality interactions between students, their peers, and faculty around intellectually meaningful subjects provides the most productive gains in terms of students' learning outcomes." 2 The authors argued that the "... learning environment increases the motivation of students, which, in turn, increases their learning outcomes. Learning outcomes show a significant relationship with success in the initial phase of graduates' careers. Furthermore, success in subsequent phases of one's career is influenced by experience gained by students during their involvement in extra-curricular activities." ${ }^{2}$ The authors concluded that the "...learning environment is important for students' learning as well as their involvement in extra-curricular activities", and "that these two elements of university education are determinants of career success". ${ }^{2}$

Each of the 18 responses obtained in the author's survey demonstrated the value that the author's classmates had placed on helping others. This corresponded with an absence of expressions of regrets. Many of the author's classmates had attained and surpassed their professional hopes and aspirations. Their work solved problems in their communities. Many of the author's classmates also described deeply meaningful relationships with their families and loved ones. As noted by Schneiderman and Barrera, this replacement of traditional values with egalitarian values has been trending in the United States despite the apparent absence of struc- 
ture. ${ }^{3}$ Similarly, the author had previously stated, "choosing a career in medicine is often rooted not only in a fascination with the human body and with solving the problems presented by illness or injury but also by a desire to help others."

In this much smaller scale study, the author was of the view that his classmates went on to enjoy satisfying careers and enriched lives. Although some expressed sadness over personal losses, none had regrets about what they valued or how those values would enrich their lives in the years that passed.

As with Lee and Ryu, in this analysis, the author considers pride and regrets to be self-conscious emotions only capable of qualitatively subjective measurement. ${ }^{5}$ Despite that some of the author's classmates had suffered familial tragedies, or difficult times in their careers, not a single person expressed any serious regret about their personal or professional choices. ${ }^{6}$ The absence of regret, when considered in the context of the drive for meaning, suggests to the author that all of his classmates lived lives of deep meaning and value. A person's survival in a career, family, or life in general, is tied strongly to the durability of one's sense of meaning. Meaning in life revolves around one's values.

The author's view, as informed by his work on the Bereavement Research Team at the Hospital for Sick Children, is that a person's moral values have a strong connection with that person's sense of self: when someone's values are egocentric, failure to attain one's egocentric objectives will have a much more devastating effect on that person's core identity. This, in turn, can negatively affect one's resilience and ability to weather such defeats. On the other hand, as Wu et al posited: "[ $t$ ] he existence of a moral compass or an internal belief system guiding values and ethics is commonly shared among resilient individuals". ${ }^{7} \mathrm{Wu}$ et al also observed that, "a study of 121 outpatients diagnosed with depression and/or an anxiety disorder showed that a low or lack of purpose in life and less frequent physical exercise were correlated with low resilience, but low spirituality prevailed as a leading predictor of low resilience"; and "similarly, purpose in life was a key factor linked to resilience in a study of 259 primary care patients with a history of exposure to a range of severe traumatic events"?

Following $\mathrm{Wu}$ et al, resilience in the face of difficulties requires a strong sense of purpose, one which affirms itself regularly by humanity and decency. ${ }^{7}$ In the author's view, those who live decently make decisions that are civilized, humane, and generous. Our actions themselves, in turn, affirm our sense of values: by acting decently, regardless of the outcome, we affirm rather than deny that which we value; and when our values are affirmed, we grow stronger and have a greater sense of purpose and accomplishment. Conversely, when we act only in the interests of ourselves, failure becomes much more intolerable, and growth is invariably stopped. Regrets pile up and become shame, shame that we are unable to part with unless we change our values.

Vermeulen and Schmidt argued that "the quality of the learning environment cannot express itself directly in the career success of its graduates. In the final analysis, it must be the behaviour of the students themselves, brought about by the learning environment, which leads to superior academic performance and, through this, to career success.”2 Defining career success is wholly subjective. Regardless, expressing one's "regrets" about career choices is a good measure: a person who has no regrets feels that he or she has achieved what they wanted to.

If we value decency over ambition, and civility over narcissism, then events that affirm those values bolster us. It is, of course, important to one's mental and emotional health to have ambition and to enjoy one's successes. However, if those are our only values, then failure will not permit growth. Personal growth requires a stable set of values, and when decency lies at the core of one's values, one grows with each act of decency. As we grow, we move away from shame, away from regret. Like the author's classmates commented, people for whom decency and civility are key values, they have no regrets beyond not having given more to their communities. This is a very strong and positive affirmation of the learning environment of the medical school class of '58 (University of Western Ontario).

\section{ACKNOWLEDGEMENTS}

The author thanks Brian Moher for his assistance in preparing this article.

\section{REFERENCES}

1. Wingard JR, Williamson JW. Grades as predictors of physicians' career performance: an evaluative literature review. J Med Educ. 1973 Apr;48(4):311-22.

2. Vermeulen L, Schmidt HG. Learning environment, learning process, academic outcomes and career success of university graduates. Stud High Educ. 2008 Jul;33(4):431-51.

3. Schneiderman G, Barrera M. Family traditions and generations. Fam Community Health. 2009 Oct-Dec;32(4):354-7.

4. Schneiderman,G. Doctors Treating Doctors. CPA Bulletin. 2000 Apr;32(2).

5. Lee OE, Ryu S. Effects of pride and regret on geriatric depression: A cross-cultural study with mixed-methods approaches. Int J Aging Hum Dev. 2017 Mar;0(0):1-20

6. Schneiderman, G. Coping with Death in the Family, Fourth Edition. Toronto: Dundurn Press; 1994; page 47.

7. Wu G, Feder A, Cohen H, et al. Understanding resilience. Front Behav Neurosci. 2013 Feb 15;7:10. 